\title{
Thermal Characterization of a Three-Dimensional (3D) Chip Stack
}

\author{
Keiji Matsumoto and Yoichi Taira \\ IBM Research - Tokyo, 1623-14 Shimotsuruma, Yamato-shi, Kanagawa-ken 242-8502, Japan
}

(Received September 4, 2009; accepted November 24, 2009)

\begin{abstract}
In order to determine appropriate cooling solutions for 3D chip stacks in various cases, it is important to have a better understanding of the total thermal resistance of a 3D chip stack. For this purpose, precise thermal resistance measurements and modeling of each component of a 3D chip stack are important. The thermal resistance of interconnection is considered to be one of the thermal resistance bottlenecks of a 3D chip stack. In this study, a steady-state thermal resistance measurement method is employed for the thermal resistance measurement of interconnection. The thermal resistance of the $200 \mu \mathrm{m}$ pitch C4's (Pb97Sn3) jointed samples are measured and the thermal conductivity of C4's is derived to be $18-24 \mathrm{~W} / \mathrm{mK}$. With regard to the thermal resistance of a silicon substrate, the thermal resistance of a silicon substrate with various interconnection pitches and diameters has already been modeled by considering the concentrated heat flow to interconnection, as presented in ICEP 2008.[15] Based on the modeled data, the thermal resistance reduction by underfill with various interconnection pitches and diameters is also studied.
\end{abstract}

Keywords: Three-Dimensional (3D) Chip Stack, Thermal Resistance, Interconnection, C4 (Controlled Collapse Chip Connection), Underfill, Back-End-of-the-Line (BEOL)

\section{Introduction}

Three-dimensional integrated circuits (ICs) are receiving increased attention for system performance enhancements without relying on further device scaling. However, because of the limited contact area and the higher circuit densities, the cooling of 3D ICs is challenging. We need better understanding of the total thermal resistance of 3D ICs, so that we can decide on appropriate cooling solutions for 3D ICs in various applications. For this purpose, we need precise thermal resistance measurements and modeling for each component of a 3D IC.

Extensive modeling studies have been carried out to investigate the thermal characteristics of 3D chip stacks. For example, Chiang et al.[1] calculated the power consumption of $3 \mathrm{D}$ ICs by incorporating active layers and interconnect joule heating. Other than the study by Chiang et al, Im et al.[2] studied the temperature rise of 3D ICs in two bonding cases, and Puttaswamy et al.[3, 4] further proposed a thermal management solution based on architectural level optimization, and Das et al.[5] investigated the temperature of a stacked FFT (Fast Fourier Transform) datapath with various numbers of stacks. Hua et al.[6] also performed thermal modeling of 3D ICs in greater detail. Chiang et al.[7-9] and Gplen et al.[10] and
Yu et al.[11] studied the effect of thermal-vias.

In contrast to wide-range modeling studies, experimental studies are quite lacking. In particular, there are very few experimental studies on the thermal resistance of the interconnections, even though the interconnections are regarded as one of the thermal resistance bottlenecks of a 3D chip stack. As Gurrum et al.[14] pointed out, the interconnections between chips and printed circuit boards (PCB) are key to the thermal resistance of a conventional $2 \mathrm{D}$ chip-to-board configuration, so in a $3 \mathrm{D}$ chip stack, the interconnections between stacked chips should also be considered in a similar way as an important factor in the thermal resistance of a 3D chip stack. Yamaji et al.[12] measured the contact thermal resistance between underfill and a chip with laser flash method. Based on their measurement results, they performed a numerical analysis of the total thermal resistance of a 3D chip stack. However, they found it difficult to measure the thermal resistance of the interconnections with the laser-flash method and they pointed out that a careful attention was necessary to achieve a uniform temperature distribution in the sample when using the laser-flash method on heterogeneous specimen, such as stacked chips with interconnections. Sweet et al.[13] measured the 
thermal resistance of 3D multi-chip modules by embedding polysilicon heaters and diode thermometers. They also did modeling with the finite element method and compared the measured results with the modeled values. However, the differences between the measured results and the modeled ones were simply attributed to the thermal resistance of the interconnections and the causes were left unclear.

This study primarily aims to experimentally obtain the thermal resistance of the interconnections. The thermal resistance measurement results of copper-tin (CuSn) interconnection has been shown in the previous ICEP,[15] and in this paper, we discuss the thermal resistance of $\mathrm{C} 4$, which is one of major interconnections for high-end applications. The term " $\mathrm{C} 4$ " is an abbreviation for "Controlled Collapse Chip Connection" and refers to Pb97Sn3 (a mixture of 97\% (by weight) lead (Pb) and 3\% tin $(\mathrm{Sn})$ ). Secondarily, based on the modeled thermal resistance of a silicon with various interconnection pitches and diameters,[15] the thermal resistance reduction by underfill in various interconnection pitches and diameters is studied.

In this paper, the term "interconnections" refers to joinings (for example, interconnections between two silicon substrates).

\section{Measurement Method}

\subsection{Measurement tool}

Our previous steady-state thermal resistance measurement method appears in the reference,[15] however there are some new modifications are performed since then, so it is explained here.

Our steady-state thermal resistance measurement method uses liquid metal as the thermal interface material (TIM, which is applied between a sample and the measurement tool) as shown in Figure 1. This involves two $\mathrm{Cu}$ blocks, a heater, a cooler, four K-type thermocouples $\left(\mathrm{T}_{1}\right.$, $\mathrm{T}_{2}, \mathrm{~T}_{3}, \mathrm{~T}_{4}$ ), and a sample which is sandwiched between the two $\mathrm{Cu}$ blocks. Each of the four K-type thermocouples is paired with another K-type thermocouple that is kept at $0^{\circ} \mathrm{C}$. (A total of eight K-type thermocouples are used in the measurements.) The four pairs of thermocouples are regulated by a Pt-resistive-thermal-sensor (Testo 735). The diameter of the eight thermocouples is $1 \mathrm{~mm}$ in this study, and future studies with thinner thermocouples should improve the accuracy. In order to realize the onedimensional heat flow, the horizontal dimension of the $\mathrm{Cu}$ blocks should be large enough compared to the vertical dimension of the $\mathrm{Cu}$ blocks. On the other hand, the sample fabrication tends to be difficult as the horizontal dimension

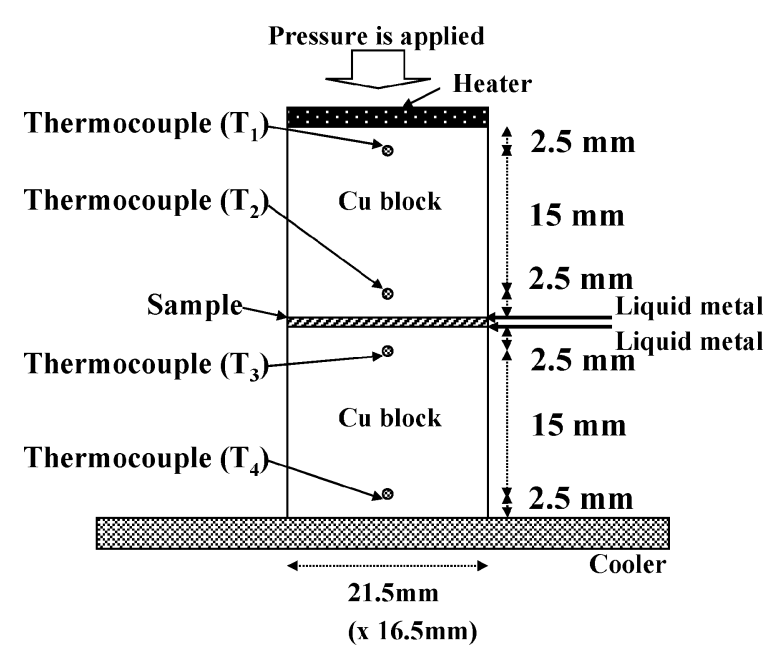

Fig. 1 Steady-state thermal resistance measurement method (cross-section view).

increases. Considering these two factors, the horizontal dimension of the $\mathrm{Cu}$ blocks and the sample is set to be 21.5 $\mathrm{mm} \times 16.5 \mathrm{~mm}$, and the vertical dimension of the $\mathrm{Cu}$ block is set to be $20 \mathrm{~mm}$. The measurements are performed at controlled temperatures to reduce the heat loss from the measurement tool to the surroundings. The surrounding temperature is controlled at $\left(T_{4}-\left(T_{3}-T_{4}\right) / 6\right)$, which is the temperature of the bottom of the $\mathrm{Cu}$ block. Liquid metal (a mixture of $75.5 \%$ (by weight) indium (In) and $24.5 \%$ gallium $(\mathrm{Ga})$ ) is applied between a sample and the two $\mathrm{Cu}$ blocks to minimize the contact thermal resistance. The thermal conductivity of In is $82 \mathrm{~W} / \mathrm{mK}$ and that of Ga is $41 \mathrm{~W} / \mathrm{mK}$ and this mixture is liquid at room temperature, so it can be compressed into a very thin film. For intimate contact between liquid metal (InGa) and a sample, the top and bottom surfaces of a sample are coated with 20 $\mathrm{nm}$ thick titanium (Ti). The thermal resistance of $20 \mathrm{~nm}$ Ti (thermal conductivity : $21.9 \mathrm{~W} / \mathrm{mK}$ ) is calculated to be lower by several orders of magnitude than the thermal resistances of samples in this study. The characteristics of InGa liquid metal TIM lead to the small contact thermal resistance and the resulting fluctuation of the contact thermal resistance is also small.

\subsection{Derivation of the thermal resistance of liquid metal TIM}

The thermal resistance of a sample is derived with Equation 1. The thermal resistance of the liquid metal TIM is derived from the measurements of two different thick silicon substrates as depicted in Figure 2. The composition of the interfaces (liquid metal between a silicon and $\mathrm{Cu}$ ) in this derivation is the same as in the measurements of the actual jointed samples (the $\mathrm{C} 4$ jointed samples.) The 
Thermal resistance of a sample $(\mathrm{K} / \mathrm{W})$

$$
\begin{array}{r}
=\frac{T_{t}-T_{b}(K)}{\text { Heat flow }(\mathrm{W})}-2 \mathrm{~A} \\
\text { Thermal resistance } \\
\text { of liquid metal TIM }
\end{array}
$$

Where

$$
\begin{aligned}
& \mathrm{T}_{\mathrm{t}}=\mathrm{T}_{2}-\left(\mathrm{T}_{1}-\mathrm{T}_{2}\right) / 6 \\
& \mathrm{~T}_{\mathrm{b}}=\mathrm{T}_{3}+\left(\mathrm{T}_{3}-\mathrm{T}_{4}\right) / 6
\end{aligned}
$$

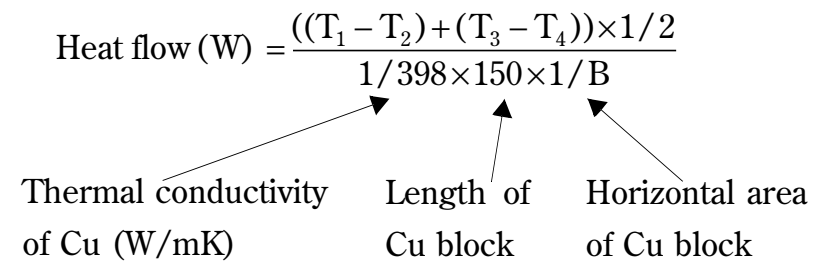

Equation 1 Derivation of the thermal resistance of a sample.

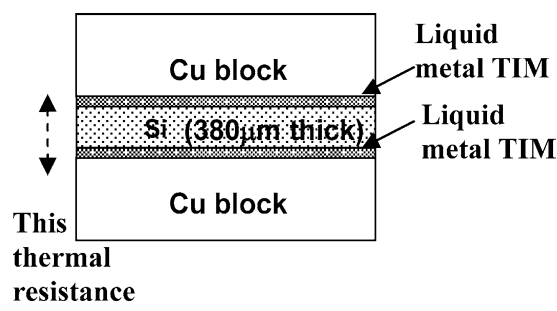

\begin{tabular}{ccc}
\hline $\begin{array}{l}\text { Measured thermal } \\
\text { resistance } \\
\left(10^{-6} \mathrm{~m}^{2} \mathrm{~K} / \mathrm{W}\right)\end{array}$ & $\begin{array}{c}\text { Calculated thermal } \\
\text { resistance of silicon } \\
\left(10^{-6} \mathrm{~m}^{2} \mathrm{~K} / \mathrm{W}\right)\end{array}$ & $\begin{array}{c}\text { Thermal resistance } \\
\text { of liquid metal TIM } \\
\left(10^{-6} \mathrm{~m}^{2} \mathrm{~K} / \mathrm{W}\right)\end{array}$ \\
\hline $\mathbf{3 - 4}$ & $\mathbf{2 . 6}$ & $\mathbf{0 . 4 - 1 . 4}$ \\
\hline
\end{tabular}

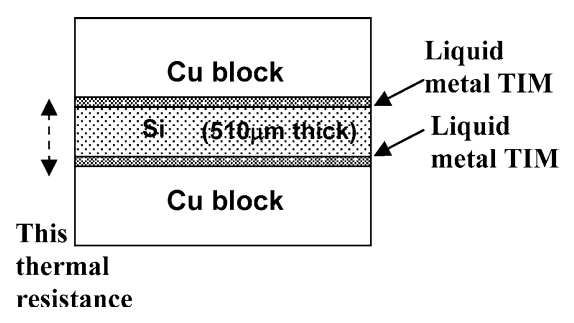

Measured thermal Calculated thermal Thermal resistance resistance resistance* of silicon of liquid metal TIM

\begin{tabular}{ccc}
$\left(10^{-6} \mathrm{~m}^{2} \mathrm{~K} / \mathrm{W}\right)$ & $\left(10^{-6} \mathrm{~m}^{2} \mathrm{~K} / \mathrm{W}\right)$ & $\left(10^{-6} \mathrm{~m}^{2} \mathrm{~K} / \mathrm{W}\right)$ \\
\hline $\mathbf{4 - 5}$ & $\mathbf{3 . 4}$ & $\mathbf{0 . 6 - 1 . 6}$ \\
\hline
\end{tabular}

* The value is proportional to the thickness. The thermal conductivity of silicon is assumed to be $148 \mathrm{~W} / \mathrm{mK}$.

'Thermal resistance of liquid metal TIM'
$=$ 'Measured thermal resistance' -
'Calculated thermal resistance of silicon'

Fig. 2 Derivation of the thermal resistance of liquid metal TIM. measured thermal resistances of a $380 \mu \mathrm{m}$ thick silicon, including liquid metal, the interface between a silicon and liquid metal and the interface between liquid metal and $\mathrm{Cu}$ are $3 \times 10^{-6}-4 \times 10^{-6} \mathrm{~m}^{2} \mathrm{~K} / \mathrm{W}$. The calculated thermal resistance of a $380 \mu \mathrm{m}$ thick silicon is $2.6 \times 10^{-6} \mathrm{~m}^{2} \mathrm{~K} / \mathrm{W}$. The calculated thermal resistance is proportional to the silicon thickness and the thermal conductivity of silicon is assumed to be $148 \mathrm{~W} / \mathrm{mK}$. Also, the measured thermal resistance of a $510 \mu \mathrm{m}$ thick silicon, including liquid metal, the interface between a silicon and liquid metal and the interface between liquid metal and $\mathrm{Cu}$ are $4 \times 10^{-6}-5 \times$ $10^{-6} \mathrm{~m}^{2} \mathrm{~K} / \mathrm{W}$. The calculated thermal resistance of the 510 $\mu \mathrm{m}$ thick silicon is $3.4 \times 10^{-6} \mathrm{~m}^{2} \mathrm{~K} / \mathrm{W}$. By subtracting the calculated thermal resistance of silicon from the measured thermal resistance, and considering the accuracy of the measurement, the thermal resistance of liquid metal TIM should be between $0-2 \times 10^{-6} \mathrm{~m}^{2} \mathrm{~K} / \mathrm{W}$.

\section{Results and Discussions}

\subsection{Thermal resistance measurement of $200 \mu \mathrm{m}$ - pitch-C4 jointed sample}

The jointed samples in this study are composed of 200 $\mu$ m-pitch-C4 sandwiched between two silicon substrates as illustrated in Figure 3. The upper silicon is $725 \mu \mathrm{m}$ thick, and the lower one is $640 \mu \mathrm{m}$ thick. The size of the upper silicon is $16.5 \mathrm{~mm}$ by $21.5 \mathrm{~mm}$ and that of the lower silicon is $20.5 \mathrm{~mm}$ by $24 \mathrm{~mm}$. In the following, the size of the lower silicon is taken as $16.5 \mathrm{~mm}$ by $21.5 \mathrm{~mm}$ (the same as that of the upper silicon), and it is confirmed by modeling that this does not influence the measured thermal resistances in this study.

The thermal resistances of the jointed samples are measured to be $39 \times 10^{-6}-44 \times 10^{-6} \mathrm{~m}^{2} \mathrm{~K} / \mathrm{W}$ (Sample No.1) and $43 \times 10^{-6}-48 \times 10^{-6} \mathrm{~m}^{2} \mathrm{~K} / \mathrm{W}$ (Sample No.2). The thermal conductivity of $\mathrm{C} 4$ is derived by comparisons with the modeled values (using the finite-element-method) as follows. The model of the jointed sample is built as depicted in Figure 4 (in which the periodic boundary condition is set at the lateral surfaces of the model). The thermal resistances of the jointed sample are modeled by changing the

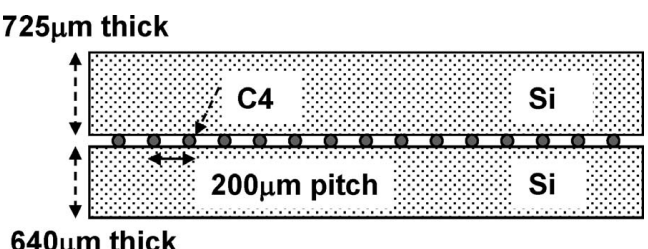

Fig. 3 C4 jointed sample (cross-section view). 
thermal conductivity of $\mathrm{C} 4$ (Figure 5 ). When the thermal conductivity of $\mathrm{C} 4$ is set to be $24 \mathrm{~W} / \mathrm{mK}$, the modeled thermal resistance is $39 \times 10^{-6} \mathrm{~m}^{2} \mathrm{~K} / \mathrm{W}$. When the thermal conductivity of $\mathrm{C} 4$ is set to be $18 \mathrm{~W} / \mathrm{mK}$, the modeled thermal resistance is $48 \times 10^{-6} \mathrm{~m}^{2} \mathrm{~K} / \mathrm{W}$. Based on these comparisons, the thermal conductivity of $\mathrm{C} 4$ is obtained to be 18 $24 \mathrm{~W} / \mathrm{mK}$.

The value $(18-24 \mathrm{~W} / \mathrm{mK})$ is considered to include the components, such as the thermal resistance of intermetallic compounds, the contact thermal resistances between a silicon and metals of interconnections, and the contact thermal resistances between metals of interconnections. For the contact thermal resistance between metals of interconnections, Bai et al.[16] measured the contact thermal resistance between eutectic lead-tin $(\mathrm{PbSn})$ solder and $\mathrm{Cu}$ to be from $1.1 \times 10^{-6}$ to $3.3 \times$ $10^{-6} \mathrm{~m}^{2} \mathrm{~K} / \mathrm{W}$. Although the metal compositions in Bai's

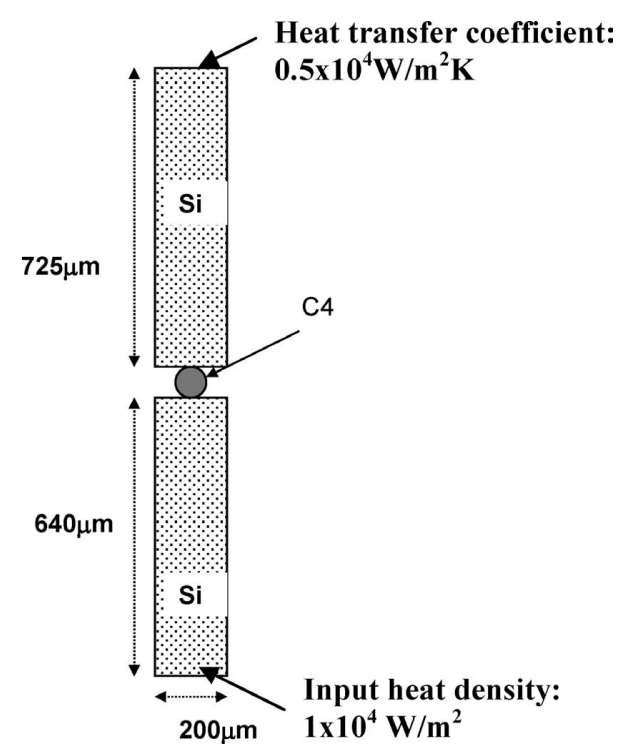

Fig. 4 The model of the $\mathrm{C} 4$ jointed sample (cross-section view).

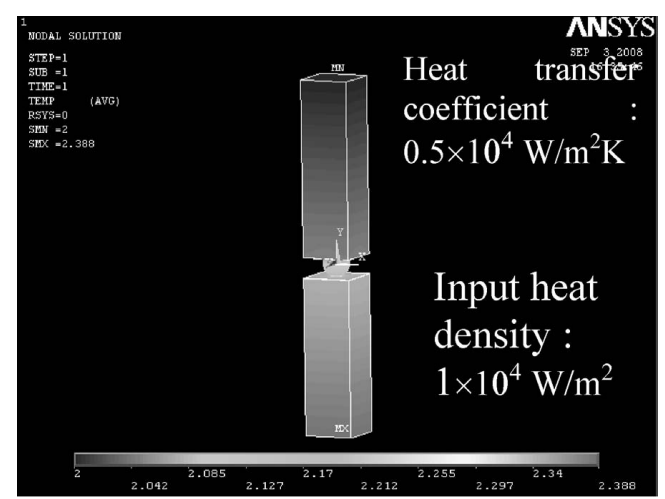

Fig. 5 Modeled temperature distribution of the $\mathrm{C} 4$ jointed sample. study differ from those in this study, it is estimated that the contact thermal resistances between metals of interconnections contribute little to the thermal conductivity of $\mathrm{C} 4$ obtained in this study.

Also the difference of the measured thermal resistance between sample No.1 and sample No.2 is estimated to be caused by the variation of interconnections. The thermal conductivities of intermetallic compounds were studied by Terada et al.[17] and Jacobsson et al.,[18] and they reported that the thermal conductivities of intermetallic compounds depend on whether they are in an ordered crystal phase or in a disordered phase. They noted that the thermal conductivities in the ordered crystal phase are higher than those in the disordered phase. The phases of the intermetallic compounds of $\mathrm{C} 4$ in this study are not yet investigated, which are subjects of our future study.

\subsection{Effect of underfill}

In most cases of $3 \mathrm{D}$ chip stacks, underfill is supposed to be used for the improvement of mechanical reliability. Underfill is also expected to reduce the thermal resistance of 3D chip stacks, and its effect is examined by modeling.

In the previous ICEP,[15] the thermal resistance of a silicon with various interconnection pitches and diameters was modeled employing a $\mu \mathrm{m}$-scale model. Based on it, the thermal resistance reduction by underfill with various interconnection pitches and diameters is studied. The $\mu \mathrm{m}$ scale models in Figure. 6 are used (the $\mathrm{C} 4$ interconnection height is $7.5 \mu \mathrm{m}$.) and the thermal conductivity of underfill is assumed to be $0.4 \mathrm{~W} / \mathrm{mK}$. The thermal resistance of the model is derived by the difference between the average temperature of the top surface and that of the bottom surface of the model and they are depicted in Table1. It indicates when the area ratio of interconnection is the same in $10 \mu \mathrm{m}$ pitch, $20 \mu \mathrm{m}$ pitch, $50 \mu \mathrm{m}$ pitch, $100 \mu \mathrm{m}$

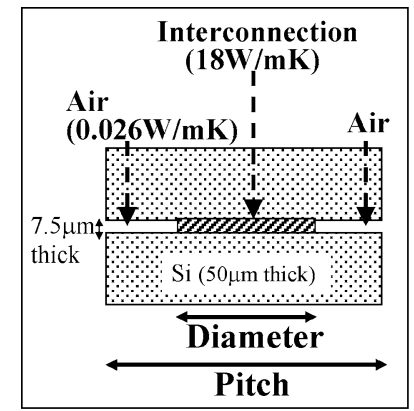

(A)

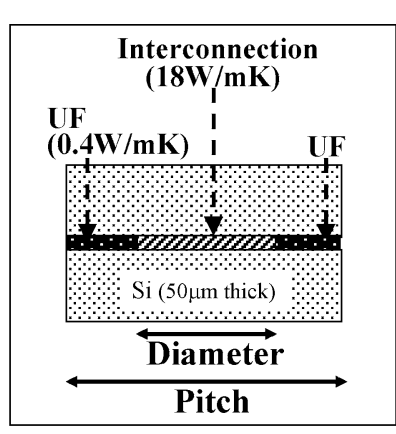

(B)
Fig. $6 \mu \mathrm{m}$-scale model of two silicons with one interconnection. (A : when air is filled, $\mathbf{B}$ : when underfill (0.4 $\mathrm{W} / \mathrm{mK}$ ) is filled.) (cross-section view). 
Table 1 Dependence of the thermal resistance reduction by underfill on the interconnection pitch and diameter. The thermal resistance reduction by underfill is calculated as follows. The difference between the modeled thermal resistance when air is filled and that when underfill is filled, is divided by the modeled thermal resistance when air is filled.

\begin{tabular}{|c|c|c|c|c|c|c|}
\hline Interconnection pitch (diameter) & $\begin{array}{c}10 \mu \mathrm{m} \\
(5 \mu \mathrm{m} \text { dia. })\end{array}$ & $\begin{array}{c}20 \mu \mathrm{m} \\
(10 \mu \mathrm{m} \text { dia. })\end{array}$ & $\begin{array}{c}50 \mu \mathrm{m} \\
(25 \mu \mathrm{m} \text { dia. })\end{array}$ & $\begin{array}{c}100 \mu \mathrm{m} \\
(50 \mu \mathrm{m} \mathrm{dia.})\end{array}$ & $\begin{array}{c}200 \mu \mathrm{m} \\
(100 \mu \mathrm{m} \text { dia. })\end{array}$ & $\begin{array}{c}500 \mu \mathrm{m} \\
(100 \mu \mathrm{m} \text { dia. })\end{array}$ \\
\hline $\begin{array}{l}\text { Modeled total thermal resistance } \\
\left(10^{-6} \mathrm{~m}^{2} \mathrm{~K} / \mathrm{W}\right) \text { (air (Fig.6(A)) }\end{array}$ & 2.88 & 2.95 & 3.11 & 3.42 & 4.09 & 28.85 \\
\hline $\begin{array}{l}\text { Modeled total thermal resistance } \\
\left(10^{-6} \mathrm{~m}^{2} \mathrm{~K} / \mathrm{W}\right) \text { (underfill (Fig.6(B)) }\end{array}$ & 2.70 & 2.75 & 2.88 & 3.12 & 3.61 & 12.30 \\
\hline $\begin{array}{l}\text { Thermal resistance reduction } \\
\text { by underfill (\%) }\end{array}$ & 6.3 & 6.9 & 7.4 & 8.8 & 11.7 & 57.4 \\
\hline
\end{tabular}

pitch and $200 \mu \mathrm{m}$ pitch, the thermal resistance reduction by underfill gradually rises as the pitch increases. (i.e., the difference between the modeled thermal resistance when air is filled and that when underfill is filled, divided by the modeled thermal resistance when air is filled, increases as the pitch increases.) When the interconnection diameter is the same in $200 \mu \mathrm{m}$ pitch and $500 \mu \mathrm{m}$ pitch, as the pitch increases, the thermal resistance reduction by underfill significantly rises.

It should be noted that in actual 3D chip stacks (3D stacked devices), a wiring layer (in other words "back-endof-the-line (BEOL)”) exists and the thermal conduction path from a transistor to interconnections is complicated. The effect of underfill is considered to depend on the thermal conduction path, and therefore the thermal conduction path from a transistor to interconnection by incorporating the back-end-of-the-line is modeled as shown in Figure 7 (Two-dimensional model). The structure of BEOL is based on the $45 \mathrm{~nm}$ node BEOL[19] and only one continuous BEOL is included in the model. The thermal conductivity of $\mathrm{SiCOH}$ is assumed to be $0.59 \mathrm{~W} / \mathrm{mK}$ (effective thermal conductivity),[20] $\mathrm{SiO}_{2}$ is $1.3 \mathrm{~W} / \mathrm{mK}$, and $\mathrm{C} 4$ is $18 \mathrm{~W} / \mathrm{mK}$, silicon is $148 \mathrm{~W} / \mathrm{mK}, \mathrm{Cu}$ is $398 \mathrm{~W} /$ $\mathrm{mK}$, respectively. Periodic boundary conditions are set at lateral surfaces of the model and the heat density $\left(1 \times 10^{4}\right.$ $\mathrm{W} / \mathrm{m}^{2}$ ) is applied at the bottom of the model and the heat transfer coefficient $\left(0.5 \times 10^{4} \mathrm{~W} / \mathrm{m}^{2} \mathrm{~K}\right)$ is set at the top of the model. The interconnection area ratio ((i.e. the interconnection area divided by the total chip area)) of Figure7. is 0.2 . The modeled temperature distribution is shown in Figure 7(B) and the modeled temperature range is $45-45.0213^{\circ} \mathrm{C}$. It means the modeled thermal resistance is $2.13 \times 10^{-6} \mathrm{~m}^{2} \mathrm{~K} / \mathrm{W}$ (the temperature at the top of the model and that at the bottom of the model are uniform, respectively and therefore the thermal resistance is

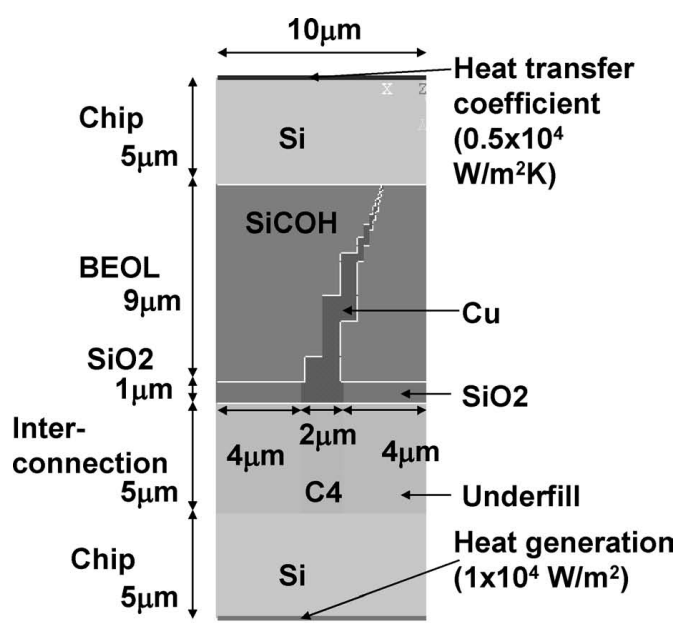

(A)

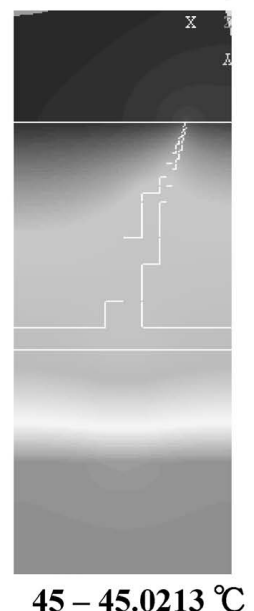

(B)

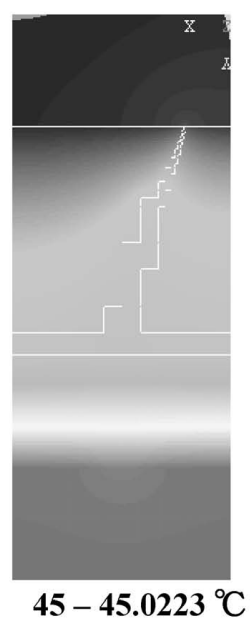

(C)

\section{$45{ }^{\circ} \mathrm{C}$ \\ $45.0233{ }^{\circ} \mathrm{C}$}

Fig. 7 (A) Two-dimensional model of BEOL and an interconnection between two chips. (B) Modeled temperature distribution. (C) Modeled temperature distribution when air is filled (instead of underfill). The thermal conductivity of underfill is assumed to be $0.4 \mathrm{~W} / \mathrm{mK}, \mathrm{SiCOH}$ is $0.59 \mathrm{~W} / \mathrm{mK}, \mathrm{SiO}_{2}$ is 1.3 $\mathrm{W} / \mathrm{mK}, \mathrm{C} 4$ is $18 \mathrm{~W} / \mathrm{mK}$, silicon is $148 \mathrm{~W} / \mathrm{mK}, \mathrm{Cu}$ is $398 \mathrm{~W} /$ $\mathrm{mK}$, respectively. 
directly derived from the modeled temperature range). As a reference, the temperature distribution when air is filled (instead of underfill) is also modeled as shown in Figure $7(\mathrm{C})$ and the modeled thermal resistance is $2.23 \times 10^{-6}$ $\mathrm{m}^{2} \mathrm{~K} / \mathrm{W}$.

The thermal resistance reduction by underfill is calculated to be $4.5 \%$, which is different from Table $1(6.3 \%)$ by $1.8 \%$. This comparison suggests that even when the model varies (Figure 7 is two-dimensional model and BEOL is incorporated, and Figure 6 (Table 1) is three-dimensional model), the derived thermal resistance reduction by underfill does not change significantly. It is estimated that in the $10 \mu \mathrm{m}$ pitch (5 $\mu \mathrm{m}$ diameter ) $\mathrm{C} 4$ interconnection, underfill with the thermal conductivity of $0.4 \mathrm{~W} / \mathrm{mK}$ contributes to reduce the thermal resistance around 4.5 to $6.3 \%$.

Further, the thermal resistance reduction by underfill, when the interconnection area ratio is 0.5 , is calculated in the same method of Figure 7, and it is below 1\%. It indicates that when the interconnection area ratio is high such as 0.5 , the thermal resistance reduction by underfill is very small.

\section{Conclusions}

We experimentally obtained the thermal conductivity of $\mathrm{C} 4$ by steady-state thermal resistance measurements. The obtained thermal conductivity of $\mathrm{C} 4$ is $18-24 \mathrm{~W} / \mathrm{mK}$. The thermal resistance reduction by underfill is also investigated by modeling and its dependence on the interconnection pitch and diameter is obtained. Further, the thermal conduction path from a transistor to an interconnection is modeled by incorporating back-end-ofthe-line (BEOL) and the thermal resistance reduction by underfill in this thermal conduction path model is also examined. In order to consider appropriate cooling solutions for various $3 \mathrm{D}$ chip stack applications, it is necessary to have better understanding of the total thermal resistance of a $3 \mathrm{D}$ chip stack. Precise thermal resistance measurements and modeling for each component of a 3D chip stack, described in this paper, are essential for the purpose.

\section{Acknowledgments}

I would like to acknowledge Kuniaki Sueoka, Sayuri Kohara and Yoshikazu Takahashi, IBM Japan, for helpful supports on measurements. I would also like to acknowledge Bing Dang, John Knickerbocker and John Magerlein, IBM T. J. Watson Research Center, for the sample preparation and for instructive discussion on measurements and modeling. I would also like to acknowledge Fen Chen, IBM Systems \& Technology Group, for instructive discussion on back-end-of-the-line.

\section{References}

[1] T. -Y. Chiang, S. J. Souri, C. O. Chui and K. C. Saraswat, "Thermal analysis of heterogeneous 3-D ICs with various integration scenarios”, International Electron Devices Meeting (IEDM), p.681, 2001.

[2] M. Im and K. Banerjee, "Full chip thermal analysis of planar (2-D) and vertically integrated (3-D) high performance ICs", International Electron Devices Meeting (IEDM), p.727, 2000.

[3] K. Puttaswamy and G. H. Loh, "Thermal analysis of a 3D die-stacked high-performance microprocessors", Great Lakes Symposium on VLSI, p.19, 2006.

[4] K. Puttaswamy and G. H. Loh, "Thermal herding: Microarchitecture techniques for controlling hotspots in high-performance 3D-integrated processors”, $13^{\text {th }}$ IEEE International Symposium on High Performance Computer Architecture (HPCA), p.193, 2007.

[5] S. Das, A. Chandrakasan and R. Reif, "Timing, energy and thermal performance of three-dimensional integrated circuits", Great Lakes Symposium on VLSI, p.338, 2004.

[6] H. Hua, C. Mineo, K. Schoenfliess, A. Sule, A. Melamed, R. Jenkai and W. R. Davis, "Exploring compromises among timing, power and temperature in three-dimensional integrated circuits ", $D A C$, p.997, 2006.

[7] T.-Y. Chiang, K. Banerjee and K. C. Saraswat, "Effect of via separation and low-k dielectric materials on the thermal characteristics of $\mathrm{Cu}$ Interconnects", International Electron Devices Meeting (IEDM)), p.261, 2000.

[8] T.-Y. Chiang, K. Banerjee and K. C. Saraswat,. "Analytical thermal model for multilevel VLSI interconnects incorporating via effect”, IEEE ELECTRON DEVICE LETTERS, vol. 23, p.31, 2002.

[9] T.-Y. Chiang and K. C. Saraswat, "Impact of vias on the thermal effect of deep sub-micron $\mathrm{Cu} /$ low-k interconnects”, Symposium on VLSl Technology Digest of Technical Papers, p.141, 2001.

[10] B. Goplen and S. Sapatnekar, "Thermal via placement in 3D ICs", ISPD, p.167, 2005.

[11] H. Yu, Y. Shi, L. He and T. Karnik, "Thermal via allocation for 3D ICs considering temporally and 
spatially variant thermal power”, ISLPED, p.156, 2006.

[12] Y. Yamaji, T. Ando, T. Morifuji, M. Tomisaka, M. Sunohara, T. Sato and K. Takahahi, "Thermal characterization of bare-die stacked module with $\mathrm{Cu}$ thorough-vias”, Electronic Components and Technology Conferences, p.730, 2001.

[13] J. N. Sweet, D. W. Peterson, D. Chu, B. L. Bainbridge, R. A. Gassman and C. A. Reber, "Analysis and measurement of thermal resistance in a 3-dimensional silicon multichip module populated with assembly test chips", $9^{\text {th }}$ Annual IEEE Semiconductor Thermal Measurement and Management Symposium, p.1, 1993.

[14] S. Gurrum, S. Suman, Y. Joshi and A. Fedorov, "Thermal issues in next-generation integrated circuits," IEEE Transactions on Device and Materials Reliability, vol. 4, p.709, 2004.

[15] K. Matsumoto, K. Sakuma, F. Yamada and Y. Taira, "Investigation of the thermal resistance of a threedimensional (3D) chip stack from the thermal resistance measurement and modeling of a singlestacked-chip”, Internatinal Conference on Electronics Packaging, p.478, 2008.

[16] J. G. Bai, Z. Z. Zhang., G.-Q. Lu and D. P. H.
Hasselman, "Measurement of solder/copper interfacial thermal resistance by the flash technique," Internatinal Journal of Thermophysics, vol. 26, p.1607, 2005.

[17] Y. Terada, K. Ohkubo, T. Mohri and T. Suzuki, "Thermal conductivity of intermetallic compounds with metallic bonds," Materials Transactions, vol. 43, p.3167, 2002.

[18] P. Jacobsson and B. Sundqvist, "Pressure dependence of the thermal and electrical conductivities of the intermetallic compounds $\mathrm{AnCu}$ ans $\mathrm{AuCu}_{3}$," J. Phys. Chem. Solids, vol. 49, p.441, 1998.

[19] S. Narasimha, K. Onishi, H. M. Nayfeh, A. Waite and M. Weybright, "High Performance 45-nm SOI Technology with Enhanced Strain, Porous Low-k BEOL, and Immersion Lithography”, International Electron Devices Meeting (IEDM), p.1, 2006.

[20] F. Chen, J. Gill, D. Harmon, T. Sullivan, B. Li, A. Strong, H. Rathore, D. Edelstein, C.-C. Yang, A. Cowley and L. Clevenger, "Measurements of Effective Thermal Conductivity for Advanced Interconnect Structures with Various Composite Low-k Dielectrics”, 42 ${ }^{\text {nd }}$ IEEE International Reliability Physics Symposium (IRPS), p.68, 2004. 